\title{
Influencia de las variables de hábitat sobre la presencia de la tortuga pímpano (Chelydra acutirostris, Peters 1862) (Chelydridae) en las quebradas Cajones y los Coclí, Quindío, Colombia
}

\author{
Influence of habitat variables on the presence of the pimpano turtle (Chelydra \\ acutirostris, Peters 1862) (Chelydridae) in the Cajones and the coclí streams, \\ Quindío, Colombia
}

\author{
Young-Valencia, Katherine ${ }^{1 *}$ Biól, Ortega-Guio, Andrés² M.Sc, Botero-Botero, Álvaro³ M.Sc.
}

${ }^{1}$ Universidad del Quindío, Programa de biología. Quindío, Colombia, ${ }^{2}$ Universidad del Pacífico, Departamento de Ciencias Naturales y Exactas, Buenaventura, Colombia. ${ }^{3}$ Universidad del Quindío; Grupo de investigación Biodiversidad y Educación Ambiental - BIOEDUQ, Fundación Neotrópica-Colombia.

\section{Key words:}

auto ecology; habitat variables; turtle's habitat; streams.

\begin{abstract}
There was analyzed the influence of the habitat variables on the presence of the Pímpano turtle (C. acutirostris) in the stream, Cajones (in Montenegro town) and The Coclí (in Quimbaya town) at Quindío department. The field phase was conducted from April to September of 2012, where 36 field trips took place, lasting one hour each $400 \mathrm{~m}$ per transect sampled. The Coclí stream has an approximate length of $2000 \mathrm{~m}$ and in these two transects were established. At the same time in the Cajones stream, with an approximate length of $3000 \mathrm{~m}$, four transects 400 $\mathrm{m}$ long and an average width of the watercourse $10 \mathrm{~m}$ were established; the transects were separated by a distance of 200 meters. At each site where a turtle was captured or sighted, they were evaluated habitat variables. To determine the influence of habitat variables on the abundance of turtles, multivariate statistical analyzes were performed. It was found that the presence of turtles in a given site, is highly related to the $\mathrm{pH}$ and sludge depth, the $\mathrm{pH}\left(\mathrm{r}^{2}=14.4793, \mathrm{p}\right.$-value $\left.=0.0417\right)$ and sludge depth $\left(r^{2}=12.1535, p\right.$-value $\left.=0.0163\right)$.
\end{abstract}

\section{Resumen}

Fue analizada la influencia de las variables del hábitat sobre la presencia de la tortuga pímpano (Chelydra acutirostris) en las quebradas Cajones (municipio de Montenegro) y Los Coclí (municipio de Quimbaya), en el departamento del Quindío. La fase de campo se llevó a cabo desde abril hasta septiembre de 2012, se realizaron 36 salidas al campo. La quebrada Los Coclí tiene una longitud aproximada de $2.000 \mathrm{~m}$ y en estos se establecieron dos transectos. A su vez en la quebrada Cajones, con una longitud aproximada de $3.000 \mathrm{~m}$, se establecieron cuatro transectos de $400 \mathrm{~m}$ de largo y un ancho promedio del cauce de agua de 10 $\mathrm{m}$; los transectos fueron separados por una distancia de $200 \mathrm{~m}$. En cada sitio donde era capturada o avistada una tortuga, fueron evaluadas las variables de hábitat. Para determinar la influencia de las variables del hábitat sobre la abundancia de tortugas, se realizaron análisis estadísticos multivariados. Se encontró que la presencia de las tortugas en un sitio determinado, estuvo altamente relacionada con el $\mathrm{pH}$ y la profundidad del lodo, el $\mathrm{pH}\left(\mathrm{r}^{2}=14,4793\right.$, $\mathrm{p}$-valor $\left.=0,0417\right)$ y profundidad del lodo $\left(r^{2}=12,1535, p\right.$-valor $\left.=0,0163\right)$. 


\section{Introducción}

El hábitat representa los recursos y las condiciones presentes en un área que determina la ocupación del territorio por un organismo, es la suma de los requerimientos específicos que son necesarios para los organismos de una especie. Estos recursos incluyen el alimento, cobertura, agua y factores que permiten a cada especie sobrevivir y reproducirse con éxito (UREÑAARANDA, 2007). De esta manera, la importancia de la evaluación del hábitat de cualquier especie animal se encuentra en la búsqueda de los parámetros claves que regulan su presencia y su dinámica poblacional en un lugar determinado, por lo que evaluar el hábitat como recurso primario es imprescindible ya que el hábitat es lo que permite a la fauna existir (UREÑA-ARANDA, 2007).

Desde el punto de vista estructural todo ecosistema (acuático o terrestre), se compone de factores bióticos y abióticos, dentro de una dinámica de interrelación definida y delimitada por estos mismos como una composición dentro del ecosistema y las condiciones edafológicas. El ecosistema acuático ya sea estuario, laguna, charca estacional, embalse, quebrada o río; se compone de elementos que dependen de los aportes alóctonos y de la capacidad de reciclamiento de materia orgánica (ROLDÁN, 2003). Entre los factores abióticos están temperatura, luz, nutrientes, $\mathrm{pH}$, gases disueltos, sustrato, entre otros. La interrelación de los factores bióticos y abióticos se define en una dinámica en la que las especies presentes juegan un papel de selección, dentro de sus propias relaciones interespecíficas e intraespecíficas (ROLDÁN, 2003).

La tortuga pímpano (C. acutirostris) aunque se reporta que puede habitar cualquier cuerpo de agua dulce con un rango altitudinal entre los 970-1.250 m.s.n.m, en los departamentos de Valle de Cauca y Quindío como lo demuestran los trabajos de MEDEM (1977), MOSQUERA y MURILLO (2003), MUNERA y REGALADO (2009), YOUNG-VALENCIA et al. (2014), presenta preferencia hacia las lagunas y charcas de aguas turbias con baja corriente y poco profundas, que tengan fondos lodosos y abundantes troncos caídos, así como una frondosa vegetación acuática y ribereña (RUEDA-ALMONACID et al; 2007). Debido a que C. acutirostris permanece la mayor parte de su tiempo bajo el agua, el ecosistema acuático sería el resultado de la interacción de estos organismos con la calidad físico y química del agua, la atmósfera y el medio terrestre que lo rodea; sin embargo, se desconocen las variables que determinan la presencia de estos organismos en algunos cuerpos de agua. Por lo cual, el objetivo de este estudio fue identificar y describir el hábitat y microhábitat de $C$. acutirostris, estableciendo las variables físicas y químicas que determinan la presencia de la especie en la quebrada Cajones y Los Coclí, en el departamento del Quindío, Colombia.

\section{Materiales y Métodos}

Este estudio continua con los resultados y análisis que se obtuvieron durante el tiempo de muestreo realizado por YOUNG-VALENCIA et al. (2014) en relación a la densidad y estructura de esta población de tortugas en la quebrada Cajones y Los Coclí.

Área de estudio. El área de estudio se circunscribe en la cuenca hidrográfica del río La Vieja, alto Cauca, Colombia, donde fueron seleccionadas dos quebradas del departamento del Quindío. La quebrada Cajones, la cual aflora después del casco urbano de Montenegro; en medio de su recorrido se une con la quebrada Chochalito que viene del municipio de Montenegro y finalmente desembocan en el río Espejo, recorriendo los predios pertenecientes al Parque Nacional de la Cultura Cafetera; con una longitud aproximada de $3.000 \mathrm{~m}$. Sus coordenadas son: $04^{\circ} 32^{\prime} 22,08^{\prime \prime}$ de latitud norte y $75^{\circ} 46^{\prime} 6.28^{\prime \prime}$ de longitud oeste, con una altitud en promedio de 997 a los 1.250 m.s.n.m. (YOUNGVALENCIA et al., 2014). La quebrada Los Coclí es un tributario del río Roble, se encuentra ubicada dentro de los predios de la hacienda El Ocaso, en la vereda el Laurel, municipio de Quimbaya, a $4^{\circ} 34^{\prime} 08^{\prime \prime} \mathrm{N}$ y $75^{\circ} 51^{\prime} 03$ " O a 970 m.s.n.m. Esta quebrada cuenta con una longitud aproximada de 2.000 metros, desemboca en el río Roble (Fig.1). Ambos afluentes presentaron una matriz del paisaje dominada por guaduales, pastos y arvenses (YOUNG-VALENCIA et al., 2014).

En cada uno de los afluentes, fueron establecidos transectos de 400 metros de longitud con el ancho promedio del canal, separados entre sí por 200 metros, para garantizar independencia de los datos. En cada transecto, se procedió a la búsqueda de individuos de tortugas, desde abril hasta septiembre del 2012 de acuerdo con la metodología planteada por RUEDAALMONACID et al. (2007).

El sitio donde fue capturada o avistada cada tortuga se georeferenció con la ayuda de un GPS (Garmin Etrex High sensitivy $\left.{ }^{\circledR}\right)$, los registros se transfirieron a cartografía digital de la zona y se diseñó el mapa con la distribución de la especie en el programa ARCVIEW GIS 3.2. (ANTÚNEZ y MENDOZA, 1992; BANDAS, 2003). También se registraron las variables físicas del ecosistema acuático como el ancho del canal, profundidad del canal, velocidad del agua (utilizando un objeto flotante en una distancia de diez metros, por unidad de tiempo), caudal del agua (volumen de agua que fue arrastrado en una unidad de tiempo) de acuerdo a la metodología planteada por RODRÍGUEZGÓMEZ et al. (1993), tipo de sustrato (lodo, arena, roca), vegetación acuática y marginal predominante (Método de parcelas de $10 \mathrm{~m}$ de longitud por $4 \mathrm{~m}$ de ancho, para cada zona de muestreo), profundidad en 


\section{arefista colombiana \\ DE CIENCIA ANIMAL}

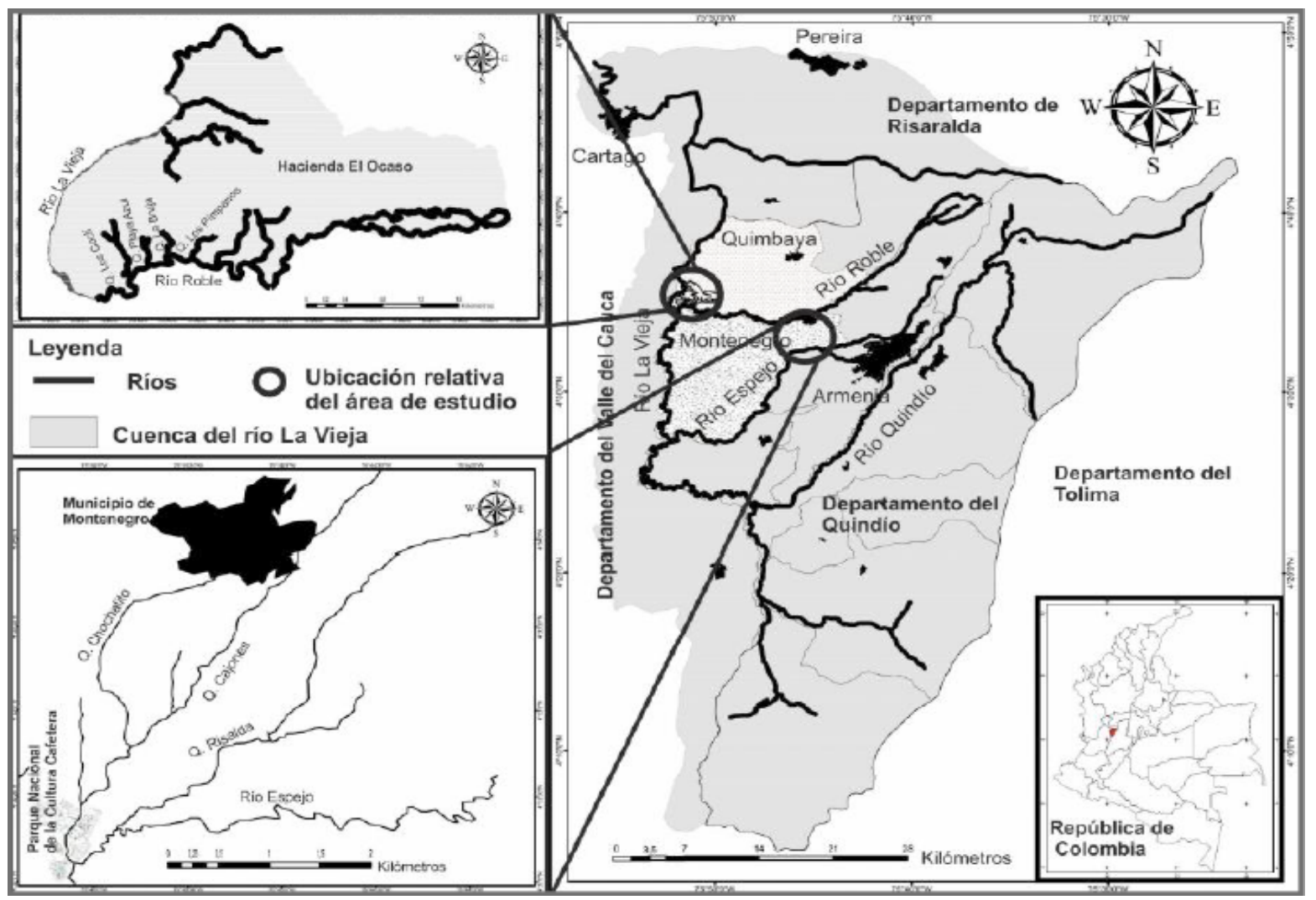

Figura 1. Mapa del Departamento del Quindío con la ubicación de las quebrada Cajones (B) y Los Coclí (A); tomado de (YOUNG-VALENCIA et al., 2014).

la que se encontró el individuo dentro del lodo (vara métrica), temperaturas del suelo, del agua y ambiental con termómetros análogos de mercurio; humedad relativa con un termohigrómetro análogo, porcentaje de cobertura del dosel con un densiómetro cóncavo, tiempo lunar basado en el calendario, para el área de estudio. También se registró el estado en el cual se encontraba la tortuga (presencia de ectoparásitos o posibles enfermedades) por inspección visual y registro fotográfico.

Los parámetros químicos y bacteriológicos del ecosistema acuático, se registraron mensualmente por transecto en cada quebrada. Las mediciones de estas variables químicas y bacteriológicas se realizaron en el centro del cauce. El oxígeno disuelto y el porcentaje de saturación, fueron medidos con un oxímetro digital (WTW® modelo OXI196-microprocesador; mg/lt); la conductividad con un conductímetro digital (HANNA® modelo HI98842; $\mu \mathrm{S} / \mathrm{cm}$ ), $\mathrm{pH}$ con potenciómetro (PIN POINT®, modelo PH370; pH 0-14). Para medir los sólidos (disueltos, suspendidos y totales), demanda bioquímica de oxígeno (D.B.O), demanda química de oxígeno (D.Q.O), porcentaje de saturación, variables bacteriológicas como coliformes totales y fecales, se tomaron muestras de agua en frascos plásticos de un litro de capacidad y envases de vidrio tipo winkler de acuerdo con la metodología recomendada por WETZEL y LIKENS (2000) y fueron trasladadas al laboratorio de aguas de la universidad del Quindío donde se tituló basado en los protocolos APHA. La caracterización de flora se realizó para cada transecto y aquellos especímenes de plantas que no se lograron identificar en campo, se trasladaron al laboratorio de botánica (CIBUQ) de la Universidad del Quindío, para su correcta identificación.

Para determinar que variables físicas, químicas y bacteriológicas se encontraban asociadas a cada transecto en la quebrada Cajones, principalmente donde se encontró el mayor número de registros de tortugas pímpano, se empleó un análisis multivariado de componentes principales (PCA), donde se incluyó las variables $(\mathrm{pH}$, conductividad, sólidos totales, sólidos totales disueltos, sólidos suspendidos, oxígeno disuelto, D.Q.O, D.B.O, coliformes totales, coliformes fecales y porcentaje de saturación de oxígeno) (Fig. 2). Para conocer la relación entre la abundancia encontrada para cada transecto en el estudio de YOUNG-VALENCIA et al. (2014) con base a las variables físicas, ambientales, 
químicas y bacteriológicas que se registraron en este estudio, se implementó una regresión múltiple con selección de variables.

El análisis multivariado no se pudo llevar a cabo para la quebrada Los Coclí debido a la escasa cantidad de transectos que generó una baja obtención de muestras para cada variable, razón por la cual los resultados para esta quebrada arrojaron una baja confiabilidad estadística.

\section{Resultados}

Interrelación entre las variables físicas, químicas y bacteriológicas de la Quebrada Cajones: Con el análisis de componentes principales efectuado para la quebrada Cajones, se obtuvo una imagen aproximada de la asociación entre las variables $\mathrm{pH}$, coliformes totales, coliformes fecales, conductividad, sólidos suspendidos, sólidos totales disueltos, sólidos disueltos, oxígeno disuelto, porcentaje de saturación, D.Q.O, D.B.O y del plano formado por las componentes 1 y 2 que reunieron el 95,3\% de la variabilidad la cual fue altamente significativa. Si bien entre menor fuera el ángulo, mayor fue la asociación entre las variables.

La varianza del componente 1, logró ser explicada por el alto aporte de la D.B.O y la D.Q.O, las cuales presentaron una alta y significativa correlación $(r=1,00$, $p=0,0016$ ), lo que indica que hubo una constante descomposición activa por acción bacteriana, seguido de los sólidos suspendidos y las coliformes fecales, producto de todos los desechos orgánicos, inorgánicos y sanitarios que llegaban a la quebrada.

La varianza del componente dos, fue explicada principalmente por los coliformes fecales y el oxígeno disuelto, seguido del $\mathrm{pH}$ y del porcentaje de saturación, igualmente como producto de la contaminación que llega a la quebrada Cajones, generando un aumento de las coliformes fecales, mayor consumo de oxígeno disuelto, disminución en los niveles de porcentaje de saturación y aumento en los niveles de $\mathrm{pH}$. Presentando una alta y significativa correlación entre las variables porcentaje de saturación y coliformes fecales $(r=0,95$, $p=0,045)$. Para el transecto 1 las variables que

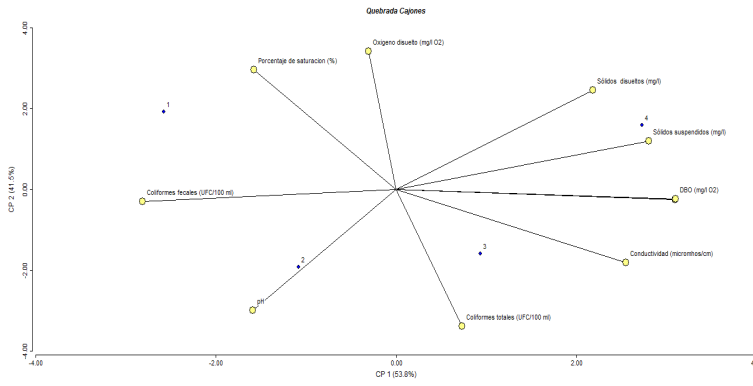

Figura 2. Análisis multivariado de componentes principales para las variables físicas, químicas y bacteriológicas tomadas en la quebrada Cajones.

estuvieron más asociadas a este fueron, porcentaje de saturación, oxígeno disuelto y coliformes fecales, para el transecto 2 la variable más asociada fue el $\mathrm{pH}$, en el transecto 3 fueron, coliformes totales y conductividad, finalmente para el transecto 4 fueron: sólidos disueltos, sólidos suspendidos, D.B.O y D.Q.O. Si bien cada variable forma parte de una asociación en conjunto para cada transecto, pero unas predominaron más que otras en los diferentes transectos, aun así, todas contribuyeron en la presencia de la especie a lo largo de la quebrada (Figura 2).

En los resultados de la asociación entre las variables de la quebrada Cajones, se evidenció el pH, coliformes totales y conductividad en los transectos dos y tres, donde se registraron las mayores densidades en el estudio realizado por YOUNG-VALENCIA et al. (2014).

Mediante la regresión múltiple, se encontró que la abundancia de la tortuga pímpano en ambos afluentes, estuvo determinada por la combinación de las variables: profundidad del lodo $\left(r^{2}=12,1535, p\right.$-valor $\left.=0,0163\right)$ y el $\mathrm{pH}\left(\mathrm{r}^{2}=14,4793\right.$, p-valor=0,0417).

Caracterización del hábitat: En la quebrada Cajones, las tortugas fueron encontradas con mayor frecuencia en zonas con profundidad del canal entre 0,1 a 1,05m. En fondos lodosos y arenosos estuvo entre 0 a $0,81 \mathrm{~m}$. La velocidad del agua se encontró entre 0 a $0,79 \mathrm{~m} / \mathrm{s}$. El porcentaje de cobertura de dosel 0 a $99,84 \%$, la humedad entre $36 \%$ a $91 \%$, hubo exceso de troncos y materia orgánica en descomposición (Tabla 1).

Tabla 1. Sustratos predominantes en la quebrada Cajones.

\begin{tabular}{cccccc}
\hline Transecto & Sustrato Roca & Sustrato Arena & Sustrato Lodo & Acumulación de Troncos & Materia Orgánica en Descomposición \\
\hline 1 & $\mathrm{X}$ & $\mathrm{X}$ & $\mathrm{X}$ & $\mathrm{X}$ & $\mathrm{X}$ \\
2 & $\mathrm{X}$ & $\mathrm{X}$ & $\mathrm{X}$ & $\mathrm{X}$ \\
3 & $\mathrm{X}$ & $\mathrm{X}$ & & \\
\hline
\end{tabular}


Sin embargo, las tortugas en la quebrada Cajones se encontraron habitando sitios con altos niveles de contaminación en el agua, indicados en los valores de la D.Q.O (2,2-151 mg/l $\left.\mathrm{O}_{2}\right)$, La D.B.O (13-92 mg/l $\left.\mathrm{O}_{2}\right)$, oxígeno disuelto bajo $\left(0,9-4,5 \mathrm{mg} / \mathrm{l} \mathrm{O}_{2}\right)$ y un alto contenido de coliformes totales (204-890UFC/100ml), además los valores en el $\mathrm{pH}$ oscilaron entre ácido y neutro $(6,4-7,2)$. La predominancia en vegetación se dio para guadua, pastos, arvenses y macrófitas acuáticas (Tabla 2).

Tabla 2. Vegetación predominante y matriz del paisaje de los cuatros transectos establecidos en la quebrada Cajones. Especies Botánicas.

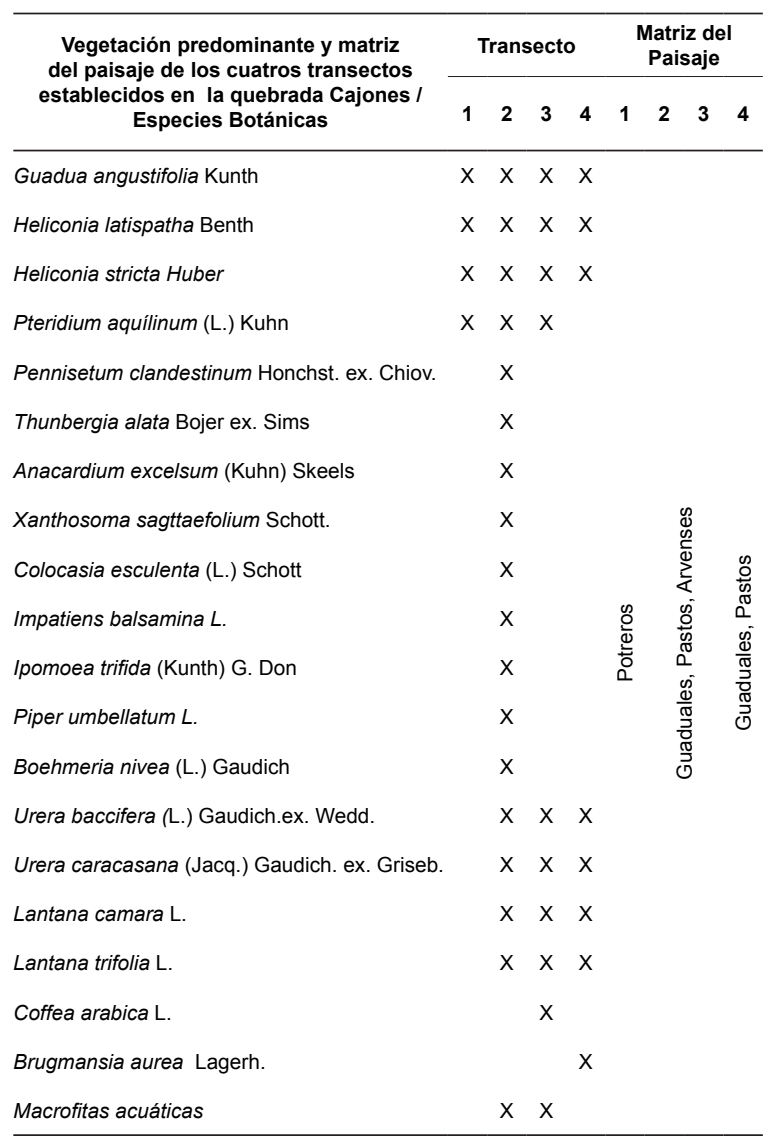

Para la quebrada Los Coclí, los sitios con mayor frecuencia de tortugas, presentaron características como: profundidad del canal entre 0,12 a 0,4 metros, fondos lodosos y arenosos entre 0 a $0,47 \mathrm{~m}$ ), baja velocidad de la corriente de agua entre 0 a $0,19 \mathrm{~m} / \mathrm{s}$, porcentaje del dosel $27,04 \%$ a $90,48 \%$, alta humedad del aire entre $53 \%$ a $89 \%$, troncos y materia orgánica en descomposición, al igual que en la quebrada Cajones, en esta quebrada fue notorio el deterioro del hábitat dado por altos niveles de contaminación en el agua indicados en los incrementos de la D.Q.O, los cuales fueron mayores para esta quebrada (18,4-246 mg/ $\left.\mathrm{IO}_{2}\right)$, la disminución de la D.B.O (11-160mg//O 2 ), bajo oxígeno disuelto $\left(1-5 \mathrm{mg} / \mathrm{IO}_{2}\right)$ y un bajo número de coliformes totales comparado con los de la quebrada Cajones (27-437UFC/100ml), además los valores del $\mathrm{pH}$ oscilaron entre ácido y neutro $(5,8-7,2)$ al igual que en la quebrada Cajones. La vegetación predominante se ubicó en los grupos de guadua, pastos, arvenses y macrófitas acuáticas (Tabla 3 ).

Tabla 3. Matriz del paisaje en los transectos 1 y 2 de la quebrada Los Coclì.

\begin{tabular}{lcc}
\hline Matriz del Paisaje Transecto & $\begin{array}{c}\text { Potreros Ganaderos, } \\
\text { Plataneras, Pastos, } \\
\text { Guaduales 1 }\end{array}$ & $\begin{array}{c}\text { Guaduales, Potreros, } \\
\text { Arvenses, Pastos 2 }\end{array}$ \\
\hline Guadua angustifolia Kunch & $\mathrm{X}$ & $\mathrm{X}$ \\
Musa paradisiaca L. & $\mathrm{X}$ & $\mathrm{X}$ \\
Heliconia latispatha Benth & $\mathrm{X}$ & $\mathrm{X}$ \\
Heliconia stricta Huber & $\mathrm{X}$ & $\mathrm{X}$ \\
Macrófitas acuáticas & $\mathrm{X}$ \\
Sustrato Roca & $\mathrm{X}$ & $\mathrm{X}$ \\
Sustrato Arena & $\mathrm{X}$ & $\mathrm{X}$ \\
Sustrato Lodo & & $\mathrm{X}$ \\
Acumulación de Troncos & & $\mathrm{X}$ \\
Materia Orgánica en & $\mathrm{X}$ & $\mathrm{X}$ \\
Descomposición & & \\
\hline
\end{tabular}

\section{Discusión}

El micro hábitat es un ambiente específico que provee a la especie las condiciones necesarias para que pueda llevar a cabo su reproducción, desarrollo, forrajeo, termorregulación y aquellas funciones ecológicas que le permitan satisfacer sus requerimientos biológicos (MEDEM, 1977). Una vez se evaluaron las variables físicas, ambientales, químicas y bacteriológicas se encontró que la abundancia de la tortuga (YOUNG-VALENCIA et al., 2014) se vio influenciada por las variables $\mathrm{pH}$ y profundidad del lodo, el hecho que la especie prefiriera sitios con mayor profundidad del lodo, se debió a que se entierra en espera de sus presas y en busca de refugio, es probable que el lodo les brinde una manera de camuflarese cuando se encuentran dentro del agua enterradas, debido a la coloración marrón oscuro de su caparazón y la apariencia de una roca.

MEDEM (1977) afirmó: "que la especie pasa por temporadas de inmovilidad y letargia, enterrada en el lodo durante la temporada seca o verano", como medida preventiva contra el desecamiento y finaliza con las primeras precipitaciones de la temporada de lluvias. Esto podría explicar porque fue más fácil capturar tortugas pímpano en épocas o días lluviosos y encontrarlas expuestas fuera del lodo. RUEDAALMONACID et al. (2007) también reportan que viven en aguas turbias, mansas y profundas con fondos lodosos, 
similar a lo establecido por MEDEM (1977), MOSQUERA y MURILLO (2003) MÚNERA y REGALADO (2009) y PÁEZ et al. (2012).

$\mathrm{El} \mathrm{pH}$ fue otro factor influyente sobre la presencia de las tortugas. HERNÁNDEZ et al. (1996) comentaron que, en la naturaleza, así como en los vertidos urbanos e industriales, se encuentran ácidos y bases, los cuales modifican ampliamente el $\mathrm{pH}$ de las aguas; oscilaciones significativas en el valor del $\mathrm{pH}$ o valores bajos o altos, podrían significar la aparición de vertidos industriales. Por otro lado, también hablaron que es preciso controlar el $\mathrm{pH}$ para garantizar los procesos biológicos, debiéndose mantener entre los valores 6,2 y 8,5 , para no generar problemas de inhibición.

De acuerdo con lo anterior, se encontró el pH con valores concordantes para este tipo de aguas contaminadas, donde hay una descomposición constante de la materia orgánica por acción bacteriana, registrando para la quebrada Los Coclí valores de 5,8 como valor mínimo y 7,2 como valor máximo para sus dos transectos, y para la quebrada Cajones en los transectos dos y tres donde se encontró la mayor densidad de tortugas YOUNGVALENCIA et al. (2014), se registró 6,3 y 7,2 de pH. El pH óptimo permitió que el sistema se encontrara en equilibrio y que todos sus procesos se llevaran a cabo, evitando la proliferación e influyendo en la productividad de los ambientes acuáticos.

Con base en los valores obtenidos de $\mathrm{pH}$ y las densidades encontradas en cada quebrada se pudo considerar que las tortugas tienen preferencia por un $\mathrm{pH}$ con tendencia hacia la acidez, algo similar a lo encontrado por MÚNERA y REGALADO (2009). En este caso el pH de la quebrada Cajones oscilo entre los valores recomendados para mantener la productividad del ambiente acuático. Según ACUÑA et al. (1983) un pH ácido es probable que provoque alteraciones en la calcificación del caparazón, predisponiendo al ataque de invertebrados de la clase Hirudinea (Sanguijuelas), información corroborada en este estudio debido a que encontramos estos ectoparásitos adheridos a la piel y caparazón de las tortugas en la quebrada Cajones (Figura 3) igual a lo reportado por (MUNERA y REGALADO, 2009).

ACUÑA et al. (1983) también reportaron en sus estudios con hábitats acuáticos, que el $\mathrm{pH}$ igual o menor a seis, generalmente corresponde a pantanos con un estado avanzado de eutrofización, donde es común el establecimiento del lirio acuático Eichhornia crassipes, formando grandes masas de vegetación que retienen y acumulan grandes aglomeraciones de sedimentos para la formación del lodo, razón que es favorecida por el alto contenido de sólidos totales, disueltos y suspendidos, además del aumento en los niveles de conductividad. Este tipo de planta genera un entorno propicio para el establecimiento de la especie ya que muchos juveniles se ocultan entre estás, encontrando un hábitat de refugio contra depredadores y en espera de posibles presas.

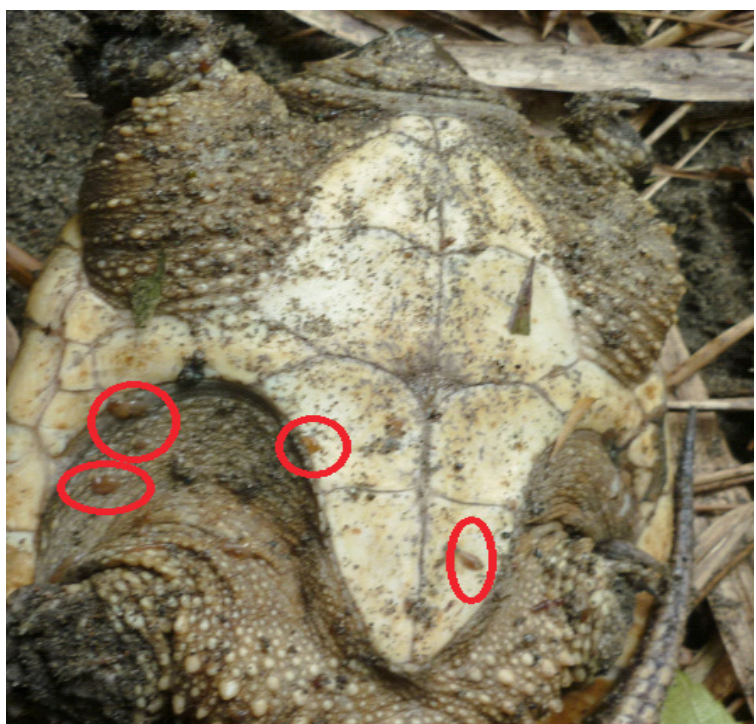

Figura 3. Tortuga con presencia de ectoparásitos adheridos a la piel y el caparazón (Quebrada Cajones)

MÚNERA y REGALADO (2009), encontraron un neonato camuflado entre un buchón de agua el cual le brindaba posibles zonas para cazar y ocultarse de depredadores. En este estudio se esperaba encontrar que la abundancia de la tortuga también estuviera influenciada por la velocidad de la corriente, pero se halló que esta variable no fue estadísticamente significativa en el análisis de regresión múltiple, debido que las dos quebradas de estudio, son sitios con bajas corrientes y la velocidad varía significativamente entre ellas, pero consideramos que la tortuga prefiere sitios con baja velocidad de la corriente debido que la mayoría se encontró en aguas lenticas, como zonas de inundación y aguas estancadas, coincidiendo con MOSQUERA y MURILLO (2003); además estas tortugas son especies poco nadadoras, prefiriendo aguas lentas y turbias donde se pueden esconder de posibles depredadores (MOLL y MOLL, 2004).

De acuerdo a las horas en las cuales fueron capturadas las tortugas, se considera que estas poseen tanto actividad diurna como nocturna, pero tuvieron mayor movimiento durante el día (YOUNG-VALENCIA et al; 2014). RUEDAALMONACID et al. (2007), también reportaron en C. acutirostris dinamismo diurno y nocturno; coincidiendo con MEDEM (1977).

Al parecer las tortugas $C$. acutirostris no se vieron limitadas por la contaminación, debido a que las mayores abundancias, se registraron en los transectos más contaminados de ambas quebradas (YOUNG-VALENCIA et al; 2014). 
En la quebrada Cajones, se obtuvieron altos valores de correlación entre coliformes totales y porcentaje de saturación, así como una alta correlación entre la D.B.O y D.Q.O producto de los agentes contaminantes que llegaban a estas fuentes, aunado a la descomposición activa por acción bacteriana. Una clara evidencia de la contaminación en la quebrada Cajones, fue una zona de agua estancada donde se acumulaban varios vertimientos residuales, esta agua era turbia, de un color verde oscuro y expelía un fuerte olor en repetidas ocasiones, en el estudio de YOUNG-VALENCIAet al. (2014) se encontraron tortugas en este mismo lugar, las cuales aparentemente no mostraron problema en estar allí.

MÚNERA y REGALADO (2009) registraron en su estudio llevado a cabo en el río Roble y Espejo, que la contaminación no fue un factor limitante en la distribución de $C$. acutirostris, debido que sus mayores registros se dieron en las zonas donde se presentó la mayor contaminación y citaron resultados similares obtenidos en C. serpentina de Norte América donde toleraba una variedad de ambientes contaminados, incluyendo polución por químicos, pesticidas, bifenil policlorados (PCBs) y metales pesados (MOLL y MOLL, 2004).

Es posible que algunos parámetros contaminantes ayudaran a generar condiciones favorables para el hábitat de la tortuga, pero esto no quiere decir que prefieran ambientes contaminados o pasar de un ecosistema conservado a uno degradado, es factible que la falta de hábitat o limitaciones en su área y la necesidad por suplir sus propios requerimientos las obligue a estar allí, llevándolas a tolerar estos tipos de ambientes. MOLL y MOLL (2004), describen que hay especies de tortugas generalistas que toleran una gran cantidad de contaminantes y pueden llegar a vivir en ambientes alterados, además ANDERSON (1965) citado por MOLL y MOLL (2004), informó que los pescadores del río Mississippi habían observado un aumento de tortugas en las zonas con moderada contaminación por aguas residuales. Sin embargo, pese a la resistencia a la contaminación que manifestó la tortuga pímpano en estas quebradas, el estado de salud pudo verse comprometido, debido que en la quebrada Los Coclí se encontró una hembra grávida con aparente desnutrición, reportado en YOUNG-VALENCIA et al. (2014), y en la quebrada Cajones se encontraron varias tortugas con caparazones blandos aparentemente descalcificados, con los tomium quebrados y presencia de ectoparásitos, al igual que un juvenil con aparente infección cutánea que comprometía el caparazón, con edema generalizado, lo cual pudo indicar una severa hipoproteinemia y un posible compromiso renal y/o hepático que es necesario evaluar en la población (Com. pers. A. TORRES-MEJÍA, 2013) (Figura 4). SOLLA et al. (1998) publicaron que la tolerancia a la carga de contaminantes provocaba un desequilibrio en los niveles de estrógeno y testosterona y que la acumulación de cargas contaminantes afectaba el desarrollo de los huevos.

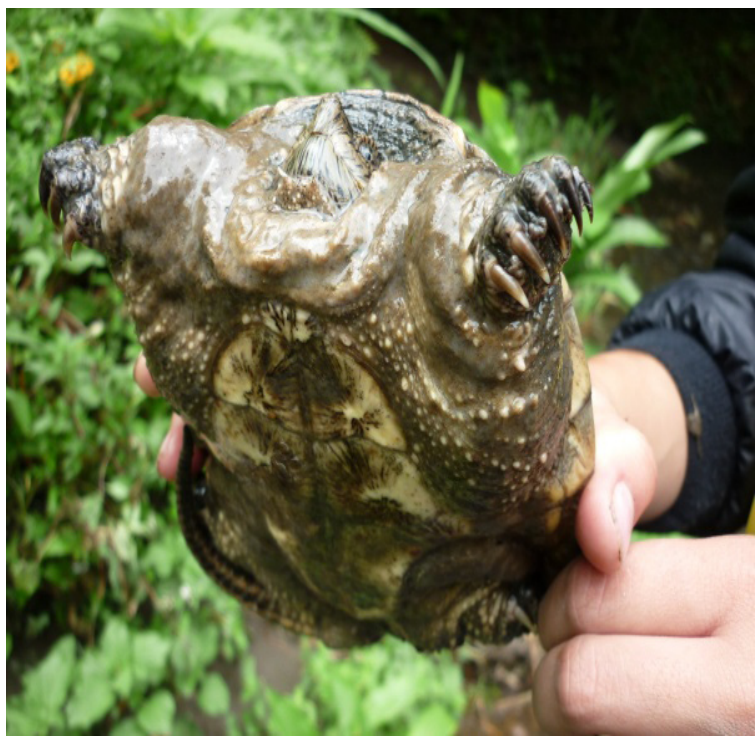

Figura 4. Tortuga juvenil con aparente infección cutánea y edema generalizado (Quebrada Cajones)

\section{Conclusión}

Las variables $\mathrm{pH}$ y profundidad del lodo, determinaron la abundancia de $C$. acutirostris para la quebrada Cajones y la quebrada Los Coclí. Sin embargo, la presencia de la especie también se vio asociada a zonas con sustratos lodosos, palizadas, abundante vegetación acuática, baja velocidad en la corriente, zonas de inundación, aguas turbias y zonas de anidación. Al parecer la especie no se ve limitada en su distribución por la contaminación del agua; sin embargo, pese a la resistencia a la polución que están manifestando en estas quebradas, el estado de salud de los individuos parece estar comprometido.

Agradecimientos: Los autores agradecen: Programa de Biología, Almacén de Laboratorio de Biología, Laboratorio de Aguas, por facilitar el préstamo de los equipos y análisis necesario. Al grupo de investigación y asesoría en estadística de la Universidad del Quindío, por el acompañamiento en el procesamiento de los datos. Parque Nacional de la Cultura Cafetera, por facilitar las instalaciones para la ejecución de este trabajo y a los auxiliares de campo, Edilberto Quintero, Santiago Styles, Laura I. Roso Jaramillo, Luisa F. Franco, Jhon Kenneddy Paniagua, Ángela M. Morales Trujillo, Jhonatan Culma y Jhon Deiber. 


\section{Referencias}

ACUÑA, M.R.; CASTAING, A.; FLORES, F. 1983. Aspectos ecológicos de la distribución de las tortugas terrestres y semiacuáticas en el Valle central de Costa Rica. Rev. De Biol. Trop. 31 (2):181-192.

ANDERSON, R.V.; GUTIERREZ, M.L.; ROMANO, M.A.1965. Turtle habitat use in a reach of the upper Mississippi River. J. Freshwater Ecol.17:171.

ANTÚNEZ, A.; MENDOZA, M. 1992. Factores que determinan el área de distribución geográfica de las especies: conceptos, modelos y métodos de análisis. Monogr. Herpetol. 2:51-59.

HERNÁNDEZ, A.; HERNÁNDEZ, A.; GALÁN, P. 1996. Manual de depuración uralita. Sistemas para depuración de aguas residuales en núcleos de hasta 20.000 habitantes. Editorial Paraninfo. Madrid.

MEDEM, F. 1977. Contribución al conocimiento sobre la taxonomía, distribución geográfica y ecológica de la tortuga "Bache" (Chelydra serpentina acutirostris). Caldasia 12:41-101.

MOSQUERA-LÓPEZ, S.; MURILLO-RENDÓN, S. 2003. Estado actual de la población de la tortuga pímpano Chelydra acutirostris en la quebrada Cristales del departamento del Quindío. Trabajo de grado (Biólogo). Universidad del Quindío. Facultad de Ciencias Básicas. Departamento de Licenciatura en Biología y Educación Ambiental. Colombia.

MOLL, D.; MOLL, E.O. 2004. The Ecology, Explotation and Conservation of River Turtles. Editorial Oxford University Press. New York.

MÚNERA ISAZA, C.; REGALADO TABARES, A. 2009. Distribución y abundancia relativa actual de la tortuga Pímpano (Chelydra acutirostris Peter 1862) Phillips et al.1996 en los ríos Roble y Espejo, sistema rio La Vieja, departamento del Quindío, Colombia. Universidad del Quindío. Trabajo de grado (Biólogo). Universidad del Quindío. Facultad de Ciencias Básicas. Departamento de Licenciatura en Biología y Educación Ambiental. Colombia.

PÁEZ, V.P.; MORALES-BETANCOURT, M.A.; LASSO, C.A.; CASTAÑO-MORA, O.; BOCK, B.C. 2012. III. Biología y conservación de las tortugas continentales de Colombia. Serie recursos hidrobiológicos y pesqueros continentales de Colombia. Editorial Instituto de Investigación de los Recursos Biológicos Alexander Von Humboldt (IAVH). Bogotá.

RODRÍGUEZ-GÓMEZ, H.1993. Fundamentos de Acuicultura Continental. Págs.58-62. En: Villenda Jiménez, A., Mejía Benítez, H. (Eds.). Cap. III. Construcción de Estanques para Acuicultura. Edición, Instituto Nacional de Pesca y Acuicultura (INPA). Colombia.

ROLDÁN-PÉREZ, G.A. 2003. Bioindicación de la calidad del agua en Colombia. Universidad Nacional de Colombia. Editorial Universidad de Antioquia. Medellín, Colombia.

RUEDA-ALMONACID, J.V., CARR J. L., MITTERMEIER R. A., RODRÍGUEZ-MAHECHA J. V., MAST R. B., VOGT R. C., RHODIN A. G. J., DE LA OSSA-VELÁSQUEZ J., RUEDA J. N. y MITTERMEIER C. G. 2007. Las tortugas y los cocodrilianos de los países andinos del trópico. Editorial Panamericana. Bogotá.

SOLLA, S.R.; BISHOP, C.A.; DERK, G.V.; BROOKS, R.J.1998.Impact of organochlorine contamination on levels of sex hormones and external morphology of common snappings turtles (Chelydra serpentine serpentine) in Ontario, Canada. Environ health perspect.106 (5):253-60

UREÑA-ARANDA, C.A. 2007. Evaluación de hábitat de la tortuga blanca (Dermatemys mawii, Gray 1847) en humedales de la cuenca baja del río Papaloapan, Veracruz. Instituto de ecología, A.C. Xalapa, Veracruz, México. WETZEL, R.; LIKENS, G. 2000. Limnological analyses, 3 (ed) Springer Verlag. Nueva York.

YOUNG-VALENCIA, K.; ORTEGA-GUÍO, A.F.; BOTERO-BOTERO, A.2014.Densidad y estructura de las poblaciones de tortuga Pímpano (Chelydra acutirostris Peters 1862) (Chelydridae) en las quebradas Cajones y Los Coclí, departamento del Quindío Colombia. Edición. Revista de Biodiversidad Neotropical (2):149-61. 